\title{
Analisis Kenyamanan Manusia (Human Comfort) pada Sistem Pendingin Desiccant Cair Tenaga Matahari Menggunakan Konfigurasi Aliran Berlawanan (Counter Flow)
}

\author{
R. Hengki Rahmanto* \\ *Fakultas Teknik, Program Studi Teknik Mesin, Universitas Islam “45” (Unisma) Bekasi, Bekasi
}

\begin{abstract}
High water vapour content in air can cause a number of problems as for human or surrounding materials. For human a high water vapour can create physiological stress, discomfort, and also can encourage ill health. While, the cause for the environment is can accelerate the corrosion of metals, accelerate the growth of spores and mould, can reduce the electrical resistance of insulators and etc.

Desiccant systems have been proposed as energy saving alternatives to vapor compression air conditioning for handling especially the latent load and also sensible load. Use of liquid desiccants offers several design and performance advantages over solid desiccants, especially when solar energy is used for regeneration. The liquid desiccants contact the gas inside the packed tower of liquid desiccant solar cooling system and the heat transfer and mass transfer will occur. This paper is trying to study the human comfort analysis inside the packed tower of dehumidifier systems. This human comfort analysis consist of human comfort and energy that consume by the system. The results of this paper later on can be used to determine the best performance of the systems.
\end{abstract}

Key words: solar cooling, dehumidification, regeneration, lithium chloride

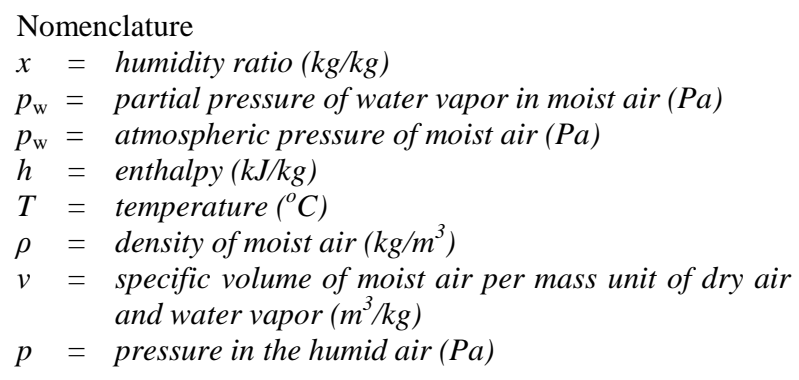

\section{PENDAHULUAN}

Kandungan air yang tinggi di udara dapat menyebabkan berbagai macam permasalahan untuk manusia dan benda-benda disekitarnya. Masalah untuk manusia, kandungan air yang tinggi di udara dapat menyebabkan tekanan fisiologis, ketidaknyamanan dan dapat menyebabkan masalah kesehatan. Sementara itu, untuk lingkungan dapat menyebabkan percepatan korosi pada logam, mempercepat pertumbuhan spora dan jamur, mengurangi hambatan listrik pada insulator dan lain sebagainya [1].

Dalam dunia industri kendali, kelembaban udara memiliki peran yang sangat besar untuk menghasilkan material dengan kualitas tinggi yang diinginkan. Sebagai contoh adalah kendali kelembaban di industri percetakan, untuk beberapa proses percetakan kertas dilewatkan ke beberapa mesin percetakan jadi kondisi udara tertentu diperlukan untuk menjaga kualitas dari cetakan. Berbagai masalah lain yang disebabkan oleh kelembaban tinggi adalah hadirnya medan listrik statis, pengeritingan atau kertas tergulung dan tinta yang tidak cepat kering [2].

Aplikasi lain dalam kendali kelembaban adalah pemrosesan makanan dan minuman dan industri pengalengan, berbagai macam variasi proses pembuatan roti dan kue membutuhkan kelembaban antara $40-80 \%$, produk elektrik antara $15-70 \%$, farmasi

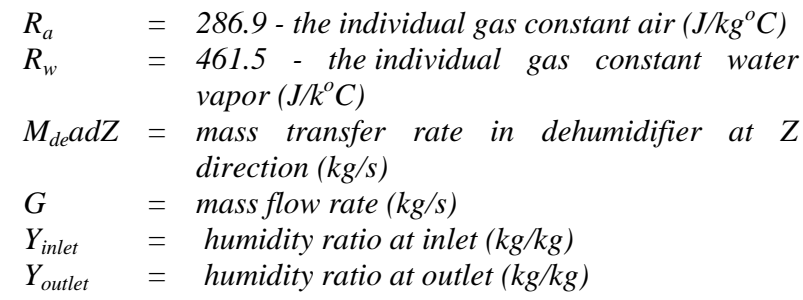

antara $15-50 \%$, industry tembakau $55-88 \%$ dan lain sebagainya [3]. Jadi industri-industri tersebut membutuhkan sebuah alat atau sistem untuk menurunkan kelembaban udara yang sering disebut dengan dehumidifier.

Kelembaban relatif dapat diturunkan dengan cara menggunakan dehumidifier tipe absorbent yaitu mempertemukan permukaan larutan lithium klorida dengan udara. Larutan lithium klorida akan menyerap kandungan uap air di dalam udara sampai kandungan uap air di dalam udara berkurang [1].

Karena pada kondisi keadaan luar ruangan yang memiliki kelembaban tinggi, sistem pendingin kompresi uap elektrik tidak dapat menyingkirkan kelembaban tanpa pertama-tama mendinginkan udara di bawah temperatur titik embun (dew point) setelah itu dipanaskan kembali (reheating). Metode ini akan menghasilkan kebutuhan energi yang sangat berlebihan dan biaya utilitas yang lebih tinggi.Dengan menggunakan sistem desiccant untuk perlakuan udara dan menyingkirkan kelembaban dari sistem pendingin konvensional sehingga memungkinkan sistem kompresi uap bertemu dengan sistem yang baru tanpa menimbulkan kerugian energi yang parah.

Sistem desiccant popularitasnya sedang menanjak karena kemampuan sistem tersebut untuk secara mandiri mengontrol tingkat kelembaban udara 
(beban laten) di gedung-gedung, dengan demikian memungkinkan sistem pengkondisi udara konvensional untuk terutama mengontrol temperatur (beban sensibel). Dalam ruang operasi rumah sakit sebagai contoh ekstrim aplikasi serius pemanasan, pendinginan dan ventilasi pada sebuah gedung, memberikan ahli bedah dan staf operasiuntuk bekerja dengan nyaman di bawah pencahayaan yang intens saat mengenakan beberapa lapis pakaian pelindung. Tidak perlu melakukan kompromi pada suatu kondisi satu ruang operasi tersebut dikarenakan kebutuhan prosedur yang sedang dijalankan di ruang yang lain dilayani oleh sistem pendingin yang sama.

Beberapa tahun belakangan ini para peneliti terapan menjadi sangat tertarik pada sistem pendingin tenaga matahari. Sistem pendingin adsorpsi siklus tertutup jelas-jelas menawarkan sebuah alternatifdibanding teknologi pendingin konvensional.Sistem tersebut memiliki kelebihan yang penting yaitu hanya membutuhkan energi panas yang rendah dibanding tingkat kebutuhan listrik yang tinggi. Pengkondisian udara biasanya dijalankan dengan sistem kompresi uap. Walaupun begitu, peningkatan pemanasan global dan dampak lingkungan dari chlorofluorocarbon (CFC) dan refrigerant sejenisnya pada lapisan ozon telah meningkatkan perhatian untuk mengembangkan sistem pengkondisi udara "ramah lingkungan". Desiccant cair menggunakan packed beds, packed tower, spray chamber (bilik semprot) atau unit sprayed coil (koil semprot). Sistem ini memiliki beberapa keuntungan termasuk di dalamnya penurunan tekanan (pressure drop) yang lebih rendah disepanjang material desiccant, cocok untuk menghilangkan debu karena filtrasi, temperatur regenerasi yang rendah dan kemudahan untuk melakukan perubahan.

\section{ALAT EKSPERIMEN DAN PROSEDUR PENGUJIAN}

Alat eksperimen dikembangkan untuk melaksanakan penelitian pada dehumidifikasi desiccant cair. Sebuah bagan dari alat eksperimen diperlihatkan pada Gbr.1. Menara dehumidifier dibangun berdasarkan panjang $40 \mathrm{~cm} \times$ lebar $40 \mathrm{~cm}$ terbuat dari akrilik sehingga dapat menampilkan visualisasi aliran. Tinggi menara tetap dan memiliki jarak $95 \mathrm{~cm}$. dalam eksperimen ini digunakan packing plastik karena lebih cocok dan lebih efisien, bobot yang lebih ringan.Packing plastik diisikan menggunakan susunan yang berurut/teratur, memiliki tinggi $3 \mathrm{~cm}$ dan diameter $3 \mathrm{~cm}$. Ruangan terisi packing plastik di dalam menara tersebut disebut packed layer. Packed layer tersebut memiliki ukuran tinggi $35 \mathrm{~cm}$, lebar $35 \mathrm{~cm}$ dan tinggi $35 \mathrm{~cm}$. Sistem packed column terdiri dari kipas, pemindah panas (heat exchanger), pendingin (chiller) dan pompa. Kipas diputar dengan motor arus searah (DC motor) yang dapat diset variasi kecepatannya untuk menyediakan pasokan udara. Ruang besar di bawah menara memberikan distribusi udara saat memasuki kolom (packed column), sementara itu akrilik dengan lubang di bagian atas menghalangi titiktitik cairan (droplet) desiccant yang terbawa oleh udara saat kecepatan udara pada variasi kecepatan kipas tertinggi. Lithium klorida tersimpan di dalam tangki akrilik sekitar 50 liter, dan setelah lithium klorida diregenerasi oleh regenerator setelah itu cairan lithium klorida akan didinginkan oleh chiller. Cairan lithium klorida didinginkan pada temperatur antara $10-20{ }^{\circ} \mathrm{C}$ dan akan menjadi cairan yang terkonsentrasi/pekat. Prosesoperasi mendasar dari dehumidifier adalah setelah desiccant cair meninggalkan regenerator dan memasuki tangki penukar panas (heat exchanger) dan setelah itu akan didinginkan dengan menggunakan chiller.Lithium klorida akan didistribusikan ke dalam packed column menggunakan spray head dipercikkan secara merata dengan konfigurasi persegi. Sistem dehumidifikasi udara diperlihatkan pada Gbr.1, sistem tersebut terdiri dari dua perulangan (loop): loop dehumidifikasi udara dan loop regenerasi desiccant cair, kedua loop tersebut menggunakan konfigurasi aliran berlawanan (counter flow) di packed column. 


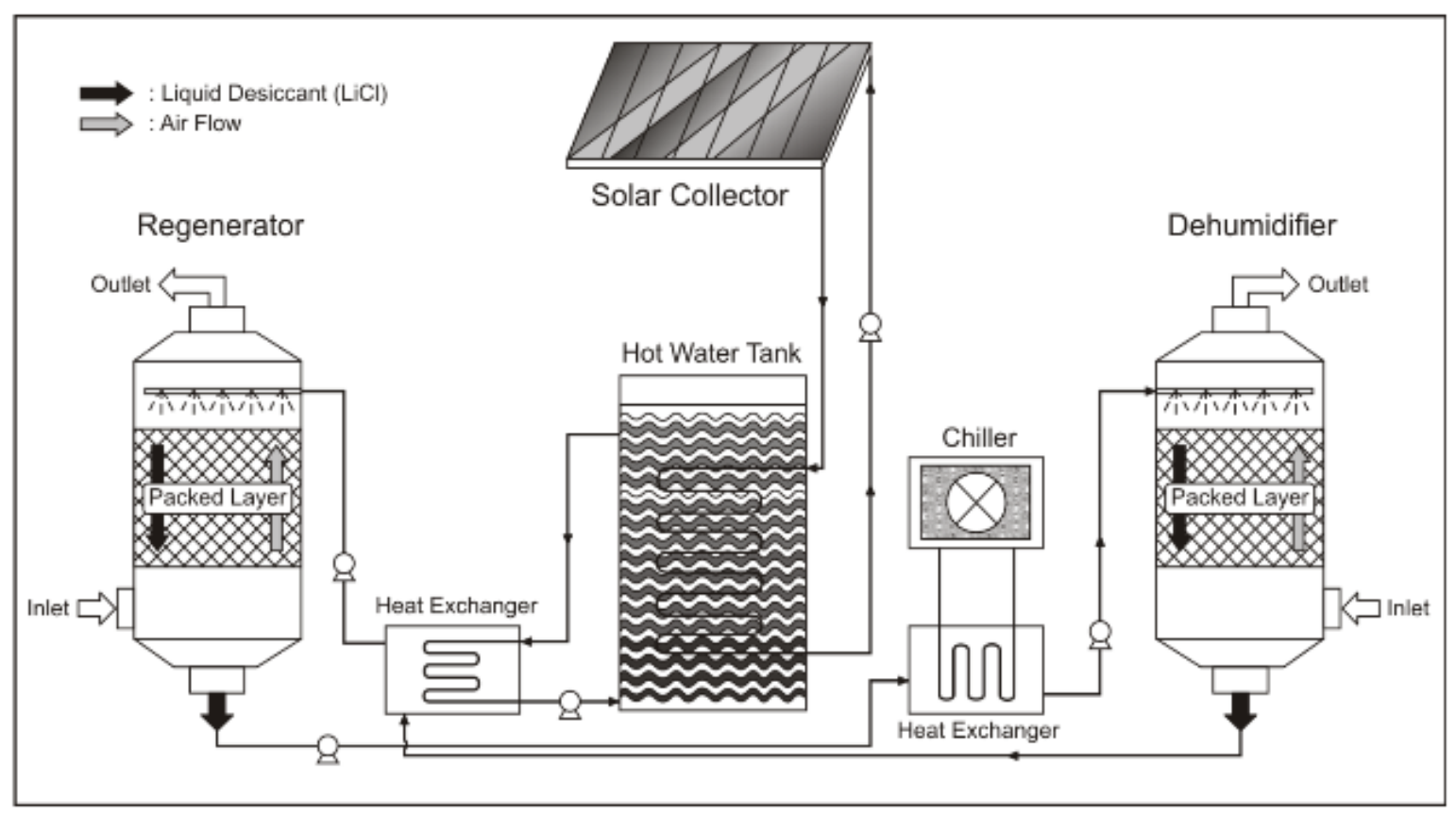

Gambar1. Regeneration and Dehumidification System

\section{ANALISIS TEORITIS}

Data yang diobservasi terdiri dari kelembaban relatif sebelum dan setelah melewati menara dehumidifier $\left(\mathrm{RH}_{\mathrm{in}}\right.$ and $\left.\mathrm{RH}_{\text {out }}\right)$, temperatur sebelum dan sesudah melewati menara dehumidifier $\left(\mathrm{T}_{\text {in }}\right.$ and $\left.\mathrm{T}_{\text {out }}\right)$ dan juga data konsumsi watt dari setiap peralatan seperti pompa, blower dan chiller. Waktu eksperimen adalah 60 menit untuk setiap variasi. Variasi tersebut terdiri dari dua kecepatan aliran udara mulai dari $3 \mathrm{~m} / \mathrm{s}$ dan 4 $\mathrm{m} / \mathrm{s}$ dan juga temperatur desiccant cair mulai dari $10^{\circ} \mathrm{C}, 15^{\circ} \mathrm{C}$ and $20^{\circ} \mathrm{C}$.

Secara total ada 6 eksperimen untuk dapat mendapatkan data semua variasi tersebut.

Dalam eksperimen ini semua analisis ini dilakukan dari sisi udara, karena lebih mudah untuk mendapatkan semua informasi dari properti udara. Dari data temperatur dan kelembaban relatif kita bisa mendapatkan banyak informasi:

1. Humidity Ratio

$$
x=\frac{0.62198 \times \mathrm{p}_{\mathrm{w}}}{\left(\mathrm{p}_{\mathrm{a}}-\mathrm{p}_{\mathrm{w}}\right)}
$$

2. Enthalpy of Moist Air

$$
\begin{aligned}
h= & \left(1.006 \frac{\mathrm{kJ}}{\mathrm{kg}^{o} \mathrm{C}}\right) T \\
& +x\left[\left(1.84 \mathrm{~kJ}^{\prime} / \mathrm{kg}^{o} \mathrm{C}\right) t\right. \\
& +(2501 \mathrm{~kJ} / \mathrm{kg})]
\end{aligned}
$$

\section{Moist Air Density}

$$
\rho=\frac{1}{v}
$$

danvadalah volume spesifik dari udara lembab per unit massa udara kering dan uap air,

$$
\begin{gathered}
v=\left(\mathrm{R}_{\mathrm{a}} \mathrm{T} / \mathrm{p}\right)\left[\left(1+\mathrm{xR}_{\mathrm{w}} / \mathrm{R}_{\mathrm{a}}\right) /\right. \\
(1+\mathrm{x})]
\end{gathered}
$$

Analisis teoritis dari perpindahan panas dan perpindahan massa diturunkan dari penelitian Treybal's [4] dalam absorpsi gas kondisi adiabatik sesuai dengan[5,6].

Analisis data dipisahkan menjadi dua analisis berbeda, namun memiliki keterkaitan yang sangat erat dikarenakan dapat menentukan variasi mana yang dapat memberikan kenyamanan pada manusia tanpa membutuhkan energi yang berlebihan.

\section{1. Analisis Kenyamanan Manusia}

Tubuh manusia adalah mamalia berdarah panas, yang secara terus menerus menghasilkan kelebihan panas. Mendapatkan energi untuk tubuh dari proses metabolisme saat mencerna makanan. Beberapa dari energi itu memperbolehkan tubuh untuk melakukan kerja; keseimbangan terjadi ketika panas bertukar dengan keadaan sekitarnya. Panas adalah pertukaran energi thermal dikarenan perbedaan temperatur dan diekspresikan dalam joule (J).

Dengan menggunakan, ASHRAE Standard 55, Thermal Environmental Conditions for Human Occupancysebagai referensi untuk analisis yang menentukan 
kondisi zona nyaman di musim dingin dan musim panas dimana $80 \%$ orang yang duduk atau orang yang sedikit aktif menganggap lingkungan tersebut secara termal dapat diterima.

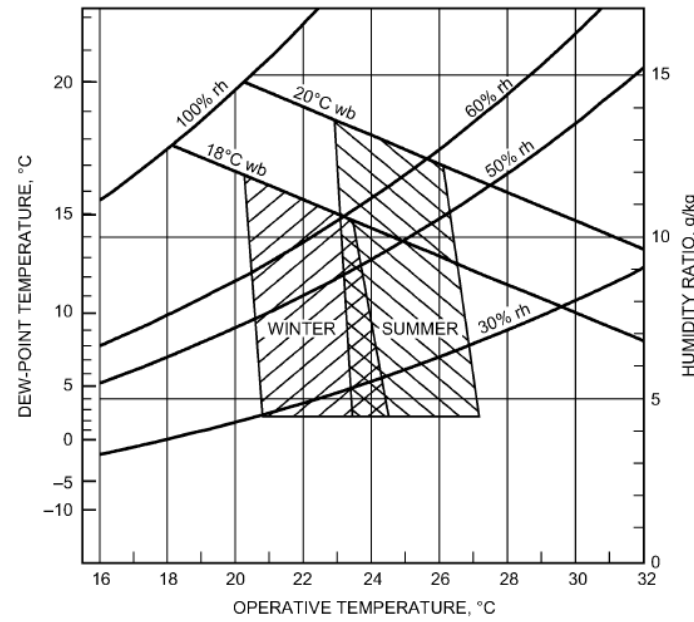

Gambar 2. ASHRAE Summer and Winter Comfort Zones [7]

\section{2. Analisis Energi}

Dengan menggunakan analisis energi kita dapat membayangkan energi yang dikonsumsi oleh setiap variasi dan menentukan konsumsi energi yang optimum.

\section{ANALISIS EKSPERIMEN}

Kenyamanan manusia ditinjau dari kombinasi dua aspek yaitu temperatur dan kelembaban relatif. Gbr 3 menunjukkan zona nyaman saat musim panas dengan menggunakan diagram psikrometri sehingga dapat memahami dengan lebih mudah berdasarkan ASHRAE standard 55.

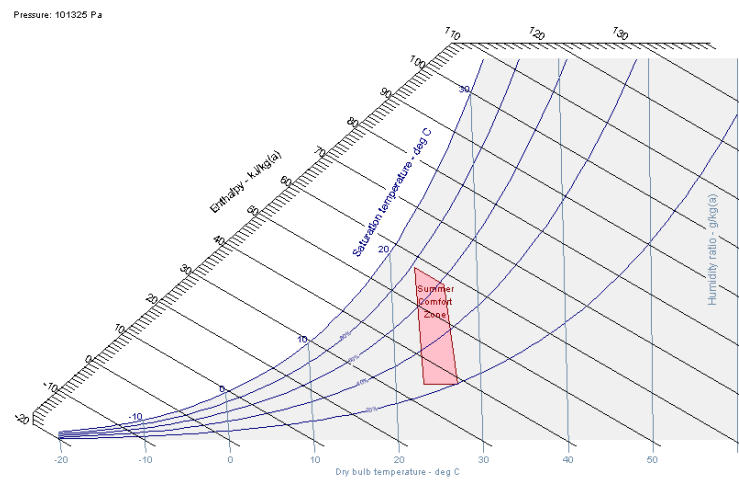

Gambar 3. Summer Comfort Zone According to ASHRAE

Gambar 4 adalah gambar inset/sisipan dari zona nyaman di musim panas ASHRAE. Titik biru adalah variasi temperatur dari lithium klorida pada $10^{\circ} \mathrm{C}$ dan aliran udara pada $3 \mathrm{~m} / \mathrm{s}$.
Dalam gambar tersebut ada titik awal dan titik akhir. Temperatur awal di dalam ruangan adalah $30.6^{\circ} \mathrm{C}$ dan $87 \%$ kelembaban relatif setelah melewati eksperimen selama satu jam temperatur akhir di dalam ruangan adalah $24.6^{\circ} \mathrm{C}$ and $43 \%$ kelembaban relatifnya. Hasil ini berdasarkan standar ASHRAE adalah berada dalam zona nyaman di musim panas.

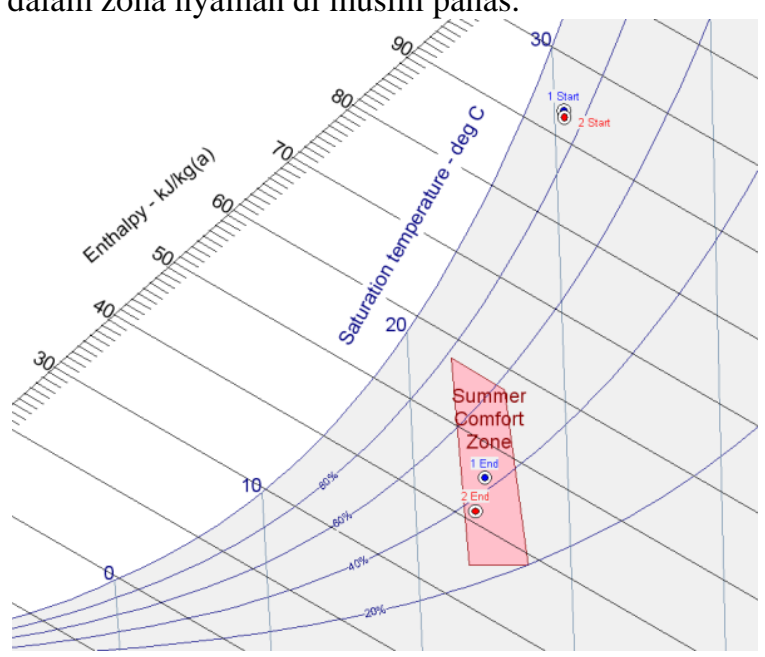

Gambar 4. Initial and Final Point of

Temperature and $\mathrm{RH}$ inside the Room

Titik merah adalah variasi menggunakan temperatur yang sama tapi memiliki kecepatan aliran udara yang berbeda yaitu pada $4 \mathrm{~m} / \mathrm{s}$. Temperatur awal pada kondisi yang sama yaitu $30.6^{\circ} \mathrm{C}$ dan kelembaban relatifnya $86 \%$. Pada akhir satu jam waktu eksperimen titik akhir merah adalah pada $23.9^{\circ} \mathrm{C}$ and $37 \%$ kelembaban relatif. Hasil ini berdasarkan standar ASHRAE adalah berada dalam zona nyaman di musim panas.

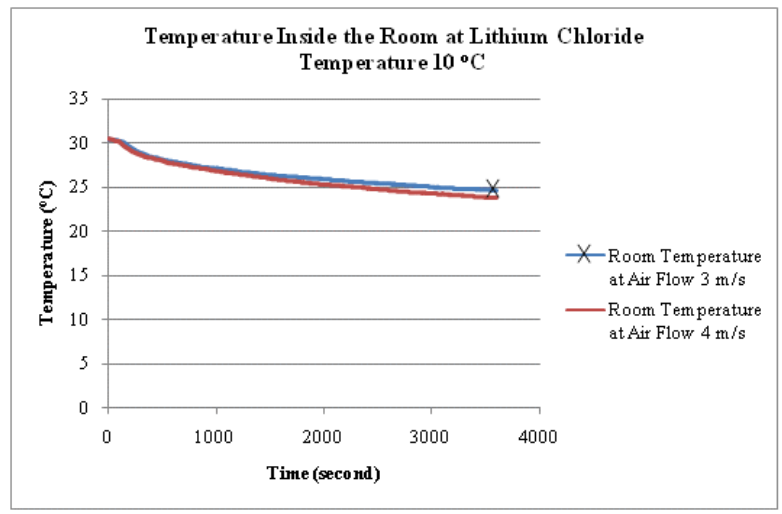

Gambar 5. Grafik Temperature inside the Room 


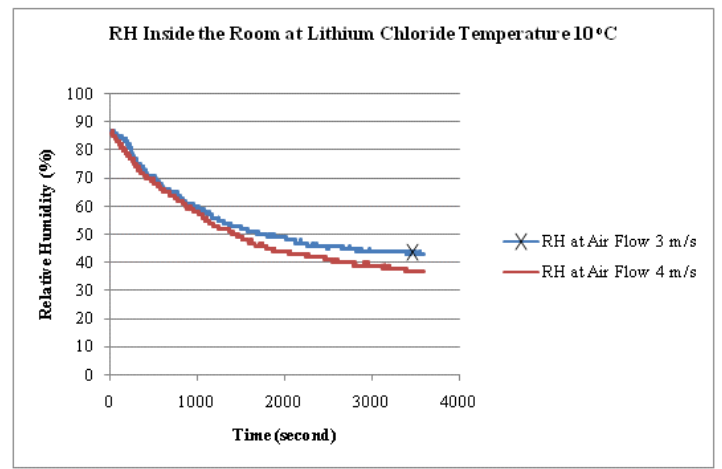

Gambar 6. Grafik Relative Humidity inside the Room

Hasil dari variasi lain juga disimpulkan bahwa semua variasi berdasarkan standar ASHRAE adalah berada dalam zona nyaman di musim panas.

Gambar 7 menunjukkan konsumsi energi optimum berdasarkan analisis energi dengan mengambil konsumsi energi rata-rata pada setiap variasi.Gambar tersebut menunjukkan pada variasi temperatur lithium klorida $10^{\circ} \mathrm{C}$ dan $4 \mathrm{~m} / \mathrm{s}$ kecepatan aliran udara memilikikonsumsi energi terbesar. Variasi terbaik adalah pada temperatur lithium klorida $20^{\circ} \mathrm{C}$ saat kecepatan aliran udaranya $3 \mathrm{~m} / \mathrm{s}$ memiliki konsumsi energi terendah dibandingkan dengan variasi yang lain.

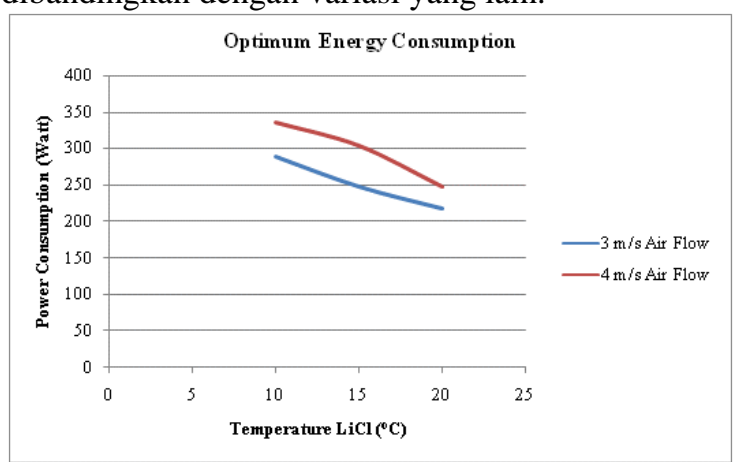

Gambar 7. Optimum Energy Consumption

\section{KESIMPULAN}

Dalam penelitian ini telah dilaksanakan eksperimen untuk mengetahui karakteristik dari sistem pendingin tenaga matahari dengan menggunakan konfigurasi aliran berlawanan (counter flow). Eksperimen ini memiliki beberapa variasi untuk melihat keterkaitan antara setiap variabel. Total ada enam variasi terdiri dari dua kecepatan aliran udara yang berbeda dan tiga temperatur desiccant cair yang berbeda.Setelah semua data didapatkan maka dilakukan dua analisis yang berbeda untuk menentukan variasi mana yang memiliki pengaturan terbaik berdasarkan dua analisis tersebut melalui sudut dan perspektif berbeda.
1. Analisis Kenyamanan Manusia

Dengan menggunakan ASHRAE standard 55, Thermal Environmental Conditions for Human Occupancy sebagai referensi untuk analisis yang merinci kondisi zona nyaman di musim dingin dan di musim dingin kita dapat melihat bahwa semua variasi tersebut berada dalam zona nyaman standar tersebut. Sebagai kesimpulan, semua variasi tersebut telah lolos zona nyaman musim panas berdasarkan standard ASHRAE.

2. Energy Analysis

Untuk melihat konsumsi energi optimum dari setiap variasi dengan mengambil komsumsi energi rata-rata pada setiap variasi tersebut.Analisis energi menunjukkan bahwa pada variasi temperatur lithium klorida $10^{\circ} \mathrm{C}$ dan kecepatan aliran udara $4 \mathrm{~m} / \mathrm{s}$ air memiliki konsumsi energi tertinggi. Variasi terbaik adalah pada saat temperatur lithium klorida $20^{\circ} \mathrm{C}$ dan kecepatan aliran udara $3 \mathrm{~m} / \mathrm{s}$ konsumsi energinya paling rendah diantara variasi yang lain.

Setelah mempertimbangkan semua aspek kita dapat menentukan bahwa pada variasi temperatur lithium klorida $20^{\circ} \mathrm{C}$ dan kecepatan aliran udara $3 \mathrm{~m} / \mathrm{s}$ adalah pengaturan (setting) terbaik diantara pengaturan yang lain. Walaupun variasi tersebut tidak memiliki perpindahan massa terbesar dan perpindahan panas terbaik namun variasi ini memiliki keseimbangan konsumsi energi terendah dibandingkan variasi lain dan yang pasti juga memiliki tingkat kenyamanan untuk manusia berdasarkan standard ASHRAE.

\section{REFERENSI}

[1] Brundrett, G.W., Handbook of Dehumidification Technology, London: Butterworths, 1987.

[2] Stoecker, Wilbert F. \& Jones, Jerold W., Refrigeration \& Air Conditioning, McGraw-Hill Companies, January 1958.

[3] Carrier Air Conditioning Company, Handbook of Air Conditioning System Design, McGraw-Hill, Inc., 1965.

[4] Öberg V. and Goswami D. Y. (1998a) Performance simulation of solar hybrid liquid desiccant cooling for ventilation air preconditioning. In Solar Engineering 1998, Proceedings of the International Solar energy Engineering Conference, pp. 176-182, ASME, Fairfield, NJ.

[5] Burns P. R., Mitchell J. W. and Beckman W. A. (1985) Hybrid desiccant cooling system in supermarket applications. ASHRAE Trans. 91 (pt. 1b), 457-468. 
[6] Chengchao F. and Ketao S. (1997) Analysis and modeling of solar liquid desiccant air conditioning system. Taiyanhneng Xuebao/Acta Energiae Sinica $18(2), 128-133$
[7] ASHRAE 2005, ASHRAE Handbook Fundamentals, American Society of Heating, Refrigerating and Air Conditioning Engineers, Inc., Atlanta GA, USA, 2005. 